\title{
Maritime Safety: To Be or Not to Be Proactive ${ }^{1}$
}

\author{
Harilaos N. Psaraftis \\ National Technical University of Athens
}

\begin{abstract}
The purpose of this paper is to address important issues as regards policy formulation in the maritime safety area. The main thesis of the paper is that there is some way to achieve a truly proactive maritime safety regime, even though there seems to be recent progress toward this end. A qualitative assessment on the nature of maritime safety policies and on the way that these are put forward is attempted, along with some opinions on possible pitfalls and on what needs to be done so that this process can be further improved.
\end{abstract}

\section{Introduction}

\begin{abstract}
"The EU now has one of the best regulatory arsenals in the world to guarantee maritime safety. It is essential that these measures should be put into effect with the utmost resolution and speed. The Commission, for its part, will continue its efforts and propose follow-up measures to complete these rules and banish the spectre of a new Erika disaster."
\end{abstract}

EU Commissioner Loyola de Palacio, commenting on the Erika I and II packages.

A number of important EU policy documents, of which the most important is the White Paper "European Transport Policy for 2010: Time to Decide”, have put increasing emphasis on maritime safety. These documents make it clear that even though the maritime transport mode's safety record is considered acceptable, and even though this mode is considered environment - friendly, more remains to be done to increase maritime safety even further.

This paper addresses important issues as regards policy formulation in the maritime safety area. As the level of maritime safety can be critically shaped as a result of maritime safety policies, it is clear that a critical assessment on the nature of these policies and on the way that these are put forward is necessary. Such an assessment is attempted in this paper, albeit qualitatively, along with some opinions on possible pitfalls and on what needs to be done so that this process can be further improved.

The rest of this paper is organized as follows. Section 2 outlines the main players in worldwide maritime safety policy-making, along with some of the obstacles they encounter in their task. Section 3 discusses the need for proactive policies. Sections 4 to 8 deal with policy issues in specific accident categories, such as tanker groundings, ship collisions, accidents due to bad weather, bulk carrier losses and Roro ferry losses. Finally section 9 presents some conclusions and recommendations.

\section{The policy-making process}

To move on effectively toward the goal of increased maritime safety, one must have a clear picture of who develops maritime safety policy and how such policy is developed. This is more complex than it may seem at first glance. Clarifying the term "maritime safety policy" is necessary at first. At its broadest interpretation, one may include any measure that falls into one or more of the following categories: Laws, rules, regulations, directives, instructions, memoranda of understanding (MOUs), resolutions, protocols, guidelines, specifications,

\footnotetext{
${ }^{1}$ WMU Journal of Maritime Affairs 1, 3-16, 2002.
} 
standards, recommendations, codes, practices, or generally any other measure that specifies, prescribes, encourages, mandates, recommends, or enforces on an on-going way specific actions that may impact maritime safety. For instance, an IMO rule on the strength of transverse bulkheads in bulk carriers, a national regulation on vessel traffic separation, a regulation on the banning of alcohol use onboard, a P\&I club rule on liability and compensation, an engine maintenance practice, and, last but not least, the US Oil Pollution Act of 1990, all may be classified under the realm of "maritime safety policy".

The main player in the international maritime safety regulatory regime is the International Maritime Organization (IMO), and specifically the International Convention on Safety of Life at Sea (also known as SOLAS), which is IMO's basic forum dealing with maritime safety. In addition to SOLAS, the IMO adopts also other measures that may impact maritime safety, either directly or indirectly. Examples are the Convention on Standards of Training, Certification and Watchkeeping of Seafarers (also known as the STCW Convention) and the High Speed Craft Code (HSC Code). The IMO does not implement or enforce regulations, that being the responsibility of member states.

IMO's policy is also to bridge the gap between new and existing ship standards, emphasize the role of the human element, shift the emphasis from the development of new to the implementation of existing standards, and generally promote a safety culture in all maritime activities. To promote a scientific approach to maritime safety, the Formal Safety Assessment (FSA) methodology has been proposed and the IMO's Maritime Safety Committee (MSC) is tasked to implement this methodology in the years ahead.

The International Safety Management (ISM) Code is seen as one of the instruments that would enhance safety for ships that are certified to comply with it. Classification societies and IACS (the International Association of Classification Societies) are expected to play a critical role in that regard. Quality shipping campaigns regard the implementation of the ISM Code as their central pillar. In parallel to the IMO, IACS is influential in the development of standards that pertain to safety.

In addition to the above, a number of other important players have key roles in the development, implementation and enforcement of maritime safety regulations. These players include flag states, port states, international bodies such as the European Union (EU), labor organizations such as the International Labour Organisation (ILO), the shipping companies themselves, and other maritime-related industries (ports, shippers, shipyards, P\&I clubs, environment groups, etc).

Collectively, maritime safety policies advanced by the above players can be said to be classified into categories that include training requirements for seafarers, certification of seafarers, fitness for work, use of alcohol and drugs, fatigue, working and living conditions onboard, common working language between crew members, ship equipment and humanmachine interface, ship-to-ship and ship-to-shore communication, vessel traffic services and vessel traffic management information services, global maritime distress and safety systems, ship reporting systems, port and harbor safety regulations, navigation and pilotage, loading, stowage and discharging, fire-fighting, search and rescue, environmental protection, design of ships, construction of ships, maintenance of ships, survival capability of ships, and emergency and evacuation procedures. Some of the above categories are further classified according to the type of ship in question (e.g., design of bulk carriers, Roro ferries, tankers, etc).

It does not take too much thought to realize that just the sheer number of players and the vast array of topics involved in the formulation of maritime safety policy may lead to some or all of the following situations: 
- Over-regulation

- Overlaps in regulation

- Inconsistencies in regulation

- Gaps in regulation

Such situations have been widely criticized by the shipping industry as contributing to both a reduction in competitiveness within the industry because of excessive regulation, and, to a lack of a comprehensive safety regime because of possible gaps in such regulation. Many industry circles feel that existing safety rules are more than adequate, but lack of enforcement or uniformity of such rules is the main factor that causes accidents. Thus, these circles profess that instead of developing new policies, the focus should be on how to best enforce existing ones.

\section{The need to be proactive}

Policies currently developed and pursued in the maritime safety area are often purported to be "proactive". Proactive means an early stage identification of factors that may adversely affect maritime safety and immediate development of regulatory action to prevent undesirable events, as opposed to just an after-the-fact ad-hoc reaction to a single accident. Methodologies such as FSA are considered as prime instruments for the development of proactive policies.

Among many other researchers, Psaraftis et al (1998a,b) present some analyses of database accidents that can lead to some conclusions on possible determining factors that are important from a statistical significance viewpoint. Annex A shows some 77 distinct casualty cause codes, taken from Det Norske Veritas's “DAMA” accident database structure.

However, FSA and other sophisticated tools are often difficult to use, and in fact are used rather seldom, particularly in cases action is needed fast. Determining the factors that are most important in a specific accident is no easy task, and may involve some non-trivial scientific analysis that can take time and effort to be carried out effectively. It is actually conceivable that the precise cause of certain accidents may take many years or may even never be ascertained precisely, as is sometimes the case in airline accidents.

So in spite of the availability of systematic tools, it is no surprise that the goal of proactive policy-making has not been followed to date as much as it should. People involved in toplevel policy-making are often under pressure from political constituencies, environment groups and especially from the media to act decisively with swift and bold moves that signal their determination to improve safety "here and now". I believe that such an environment does little justice not only to methods such as FSA, but also to the very policy-making process, and, in the final analysis, to maritime safety itself.

In fact, despite the stated proactive policy goal, it is no secret that most of the past and recent regulatory activity on maritime safety has been driven by major maritime disasters. These include the capsizing of the Herald of Free Enterprise in 1987 (193 lives lost), the grounding of the Exxon Valdez in 1989 (major pollution), the fire onboard the Scandinavian Star in 1990 (158 lives lost), the sinking of the Estonia in 1994 (852 lives lost), as well as several major bulk carrier losses (e.g. Derbyshire in 1980- 44 lives lost). The Erika accident in 1999 has spurred two major regulatory packages by the EU, the so-called Erika I and Erika II packages.

In that sense, maritime safety policy-making has been very much "reactive". In principle there is nothing wrong with such an approach, and in fact it would be a major mistake not to draw lessons from major catastrophes such as the above. However, a fundamental proviso is that the policy that is ultimately adopted correctly identifies and assesses the most important 
contributing factors of such accidents and is formulated in such a way so as to prevent such factors to appear again, or alleviate their consequences in case they do.

It is precisely this point that constitutes, in my opinion, a significant controversy on the approach to maritime safety regulatory policy: Much of the policies that have been adopted in the aftermath of major accidents focus on "engineering” or "design” solutions.

In fact, such solutions include:

- Tanker design (double hulls, double bottoms).

- Roro/ Ferry design (internal subdivisions, evacuation procedures).

- Bulk carrier design (transverse bulkheads, double hulls).

However, there has been ample evidence, including a number of quantitative analyses, that support the basic premise that most maritime accidents (and most notably the very accidents that have driven recent regulatory activity) are mainly due to failures in the human element link of the maritime safety chain. This means that unless this link is unambiguously strengthened, strengthening any other link (such as the one on design) is likely to produce questionable results.

The operational and economic consequences of measures such as the above are obviously non-trivial. Entire fleets of ships not complying with these policies are rendered obsolete. Ship owners are forced either to make very expensive conversions, or purchase new ships altogether. The operational capacity of ships involved is seriously affected, although benefits may accrue to unemployed seafarers, as more ships will be necessary to carry the same cargo. Shipyards have to radically alter their designs to adapt to the new rules, although obviously they will benefit from increased sales of new ships. Demand for ship scrapping capacity goes at high levels. However, the fundamental question of what are the benefits of such policies to maritime safety, (and, by extension, to the marine environment), and at what cost these benefits will come about, remains largely unanswered.

More light on these matters is shed in the sections that follow.

\section{Tanker groundings}

Torrey Canyon, 1967. Amoco Cadiz, 1978. Exxon Valdez, 1989. Erika, 1999. Every about 10 years, a catastrophic oil spill captures the world's headlines, not counting many other spills that happen in between. As far as relevant policy goes, the turning point came in 1989. Producing one of the worst oil spills in U.S. history, the tanker Exxon Valdez, later renamed Sea River Mediterranean and forever banned by federal law from revisiting Alaskan waters, is responsible for one of the most far-reaching pieces of maritime legislation. The Oil Pollution Act of 1990 (OPA' 90) stipulates, among other things, drastic changes in the design and construction of tanker vessels allowed into U.S. territorial waters, double hulls and double bottoms being the most significant required feature.

OPA'90, even though a piece of national legislation, has had worldwide implications. These implications have had drastic ramifications on the design, operation, and economics of waterborne petroleum transport, not just in the U.S., but worldwide. The central question however is, what benefits has this policy eventually produced, and at what cost?

Although it is still premature, a similar question can be asked vis-à-vis the Erika I package, which is similar in spirit as regards phasing out single-hull tankers in European waters. This package was formulated in the aftermath of the Erika oil spill, and has been already written into EU law. In addition to phasing out single-hull tankers, it also calls upon a greater control 
of the activities of classification societies and a stepped up port state control system.

I know of no analysis that has answered the above "cost-benefit" questions, which are admittedly difficult. In a sense, only time may provide answers, although it is fair to speculate that even after a long time this will be difficult to ascertain. The benefits in question will have to be calculated in terms of environmental and other economic damages averted because of the new tanker designs, for those cases where it can be documented that these designs had a tangible effect (grounding but no spill because of it). The costs will have to be calculated in terms of both additional construction cost and reduced revenues due to lower cargo carrying capacity. No estimate of either these benefits or these costs is currently available.

Whatever these costs and benefits might be, it is widely accepted that the main reason behind both accidents was a failure in the human element part of the equation. In the Exxon Valdez case, the US National Transportation Safety Board (NTSB) determined as probable causes the use of alcohol by the ship's master, the failure of the third mate to properly manoeuvre the vessel because of fatigue, and the failure of the vessel traffic service because of inadequate manning levels, among other factors. In the Erika case, faulty inspection procedures by Italian classification society RINA and faulty maintenance procedures were speculated as probable causes.

Given the above, one cannot resist asking the obligatory question: Since no cost-benefit analysis that supported the formulation of these policies prior to their adoption is known, were OPA'90 and the Erika I package more of a 'knee-jerk' reaction to a pair of bad accidents, and as such, perhaps they missed the chance to include other elements that would really make a difference?

There is no easy answer to this question, which may be considered unfair by maritime policymakers. One could say that both pieces of legislation tackle the problem mainly in an indirect way, by providing the human element with better technology (less prone to hull rupture) in case a tanker grounding occurs. Looking at more direct ways to solve the problem, in 1993 the US NTSB proposed uniform alcohol regulations for all transport professionals, a zero blood alcohol level while on duty, and random alcohol testing as a deterrent. However, these proposals have not been accepted, leaving the old (1987) US Coast Guard alcohol regulations operational. These regulations apply to all US flag vessels and those sailing US territorial waters, and stipulate allowable alcohol levels more stringent than those recommended by the IMO STCW Convention.

Note that the EU still has not included the STCW alcohol recommendations into the training legislation that translates the STCW Convention into EU law, so it is up to each individual EU member state to decide to implement the IMO alcohol rules or not. Note also that the use of alcohol by Exxon Valdez's Captain Hazelwood (who is rumored to still have his license) has not been proven in court. The Exxon Valdez litigation battle was particularly complex and lasted many years, and the same is speculated to happen in the Erika case.

It all fairness, the Erika I package includes also other, more direct provisions, such as tighter inspections by classification societies and by port state control, that might significantly reduce the risk of such accidents. The same can be said about the Erika II package (which is not as yet officially adopted), which includes provisions for the establishment of a European Maritime Safety Agency, better information and monitoring procedures, and a compensation scheme for oil spill victims. Still, the cost-benefit issue is equally valid for most of these proposed measures. To my knowledge, there has been no such analysis to evaluate their impact prior to their adoption. 


\section{Ship collisions}

Many ship collisions are due to non-observance of rules pertaining to collision avoidance, as much as many others are due to technical malfunctions or other failures (for instance, radar malfunctions, rudder or propeller malfunctions, etc, which may lead to a collision).

Extending the same type of OPA'90 - Erika I rationale to ship collisions, one could conceivably speculate that many ships involved in collisions (not necessarily tankers) would have a better collision survivability if they had a double hull. This means that one could conceivably devise a policy or regulation that would require selected types of ships (e.g., bulk carriers, container ships, or even passenger ships) to be designed or "armored" in such a way, with the rationale that this would make the consequences of collisions less severe.

Damage stability rules notwithstanding, some people might raise eyebrows to such a policy alternative, for it could have very adverse cost implications, whereas its potential benefits might remain dubious at best. Note however that it is precisely this type of rationale that finally prevailed in the OPA '90 and in Erika I, by forcing construction and operation of double-hulled and double-skinned tankers so as to prevent pollution.

For ship collisions, even though crash-worthiness could be very important, and in spite of important R\&D being conducted on this topic, the question is how distant is this issue in terms of becoming part of the maritime safety policy-making process. Note that this same issue is already part of this process in other transport modes (most notably the automotive one, where there are very comprehensive rules on bumpers, stiffeners, and voluntary other "passive" safety means such as padding and airbags). Therefore it could, at some appropriate point in time, be introduced to the maritime sector as well, hopefully after it has been thoroughly assessed.

One could also conceivably examine policies that would better protect passengers in case a ship collision occurs. For instance, this might include wearing life-vests until the ship is in the open sea. Although such a policy looks similar to the "fasten seat belts" policy during aircraft takeoffs and landings, the concern is that it could be too cumbersome to implement on passenger ships, particularly on cruise ships. But if a cumbersome policy saves lives, it cannot be rejected outright. Application of such a policy to High Speed Craft may also be warranted. Better passenger protection in case of a collision might also entail requiring passenger ships (especially High Speed Craft) to have specially padded interiors and furniture, to alleviate the likelihood of somebody being wounded in case of a collision.

Among "active" safety measures, policies that increase safety via vessel traffic management information systems (VTMIS) should be carefully reconsidered. The fundamental difference between such systems at sea and the equivalent systems in other transport modes (most notably in air, but also in rail transport) is the degree of freedom enjoyed by a ship's master as compared to that of an aircraft pilot or a locomotive driver. Whereas the latter two are invariably subject to extremely strict centralized traffic control schemes- which leave very little freedom to act on their own, the former has significant leeway in controlling the movement of his vessel, provided some established rules for collision avoidance are followed.

The fundamental policy question here is this: Given that the rules for collision avoidance are sometimes not followed- with catastrophic results at times, would it be perhaps better to switch to a system similar to that used in air transport? After all, the air traffic control system is considered one of the main factors that have contributed to the legendary safety record of aviation. In the maritime equivalent of such a system, the ship's master would be obliged to obey the instructions of a shore-based maritime traffic controller, with little or no freedom to act on his own. Such a system would be based on a VTMIS, but there would be specific rules 
on what is to be decided by the shore controller and what by the ship's master.

To some maritime circles, even posing such a question might be considered blasphemous, on the ground of going against the sacred "freedom of the seas" tradition. However, one cannot simply dismiss such an idea on this ground alone. It should be carefully studied and assessed, and applied selectively to areas of high traffic density under the appropriate circumstances. The performance of the system might then be compared to a system that does not implement such a policy.

\section{Accidents in which bad weather is a factor}

Clearly, many ship accidents that occur in severe weather would have been averted if the ship's master had taken some or all of a number of precautionary measures, so as to avoid exposing the ship to the additional risk implied by such weather. The question is if such measures would be easier to take if an appropriate "weather-related" safety policy were in place.

A policy that is currently in place for coastal passenger ships in Greece is to ban sailings in case of very adverse weather conditions. The ban is imposed by the Greek Coast Guard as a function of the Beaufort scale, and is observed separately for Roro ferries and for smaller ships (hydrofoils, catamarans, etc). This policy was implemented after the loss of coastal passenger ship Heraklion in 1966, which claimed at least 264 lives (the ship sunk because a truck went loose and forced a side door open). As a result of this policy, casualties attributed to bad weather were virtually eliminated in Greek passenger shipping (interestingly enough, the Express Samina ferry accident which claimed 81 lives in 2000 occurred in weather below the ban limit).

The conceivable extension of such a policy to cargo vessels, and/or to vessels engaged in international trades might be considered as out of question by many circles, as again infringing on the master's freedom to command the ship (a.k.a. his status as being only "second to God" on the fortune of the ship), and because of the obvious difficulties of implementing such a policy across vast stretches of international waters. However, in view of several catastrophic losses that occurred in bad weather (the most notable of which has been the Estonia accident in 1994), a reexamination of this issue from a policy perspective is warranted, at least for some classes of vessels and for some trades. In air travel, statistical evidence has suggested some researchers in the US to recommend shutting down airports at times of thunderstorms as a way to limit the risk of air crashes, but the measure is still under discussion (Barnett, 1987, Machol and Barnett, 1988).

It is interesting that the European Commission has taken up this matter in the Erika II package, even though the precise way such a policy would be implemented (if at all) is still unclear.

If banning ship sailings altogether is considered too drastic, intermediate "market-driven" solutions could be considered. If for instance P\&I clubs adjust their premiums or their compensation schemes for those ship owners who deliberately avoid sailing in extremely bad weather conditions, this could provide a serious economic incentive toward this end.

Hopefully, some analysis would precede the decision to adopt such policies (or not to adopt them).

\section{Bulk carrier losses}

The Derbyshire accident in 1980, along with a number of other serious bulk carrier losses, 
have been responsible for the comprehensive overhaul of the IMO/IACS regulations on bulk carrier design, construction, and maintenance. These rules will have monumental consequences in bulk carrier design, operation, and economics. However, it is far from clear whether the Derbyshire loss would be averted had the ship been built and maintained according to these regulations. More relevant in this case is, in my opinion, the decision of the master to sail the ship the way he did under such adverse weather conditions. This is true not only in this case, but also in the Estonia case, and in a number of other cases as well.

The recent thesis by leading classification societies that FSA shows that double hulls should be introduced in bulk carriers too, even as a voluntary measure, suggests that one may see similar measures eventually advanced to a broader variety of ship types in the future.

In my opinion, a policy that specifies a ship to de designed in such a way so that it can sustain damage and stay intact even if operated in a questionable or even reckless fashion is a dubious policy on at least two counts. First, it does not discourage such way of operation, and it may actually encourage it at times. Second, there is no serious documentation of its benefits, vis-àvis the costs entailed in implementing it, which are also unknown.

Yet, there seems to exist, at least in my opinion, a proliferation of such policies for maritime safety matters these days. Many of them refer to "passive" safety, that is, making the ship less vulnerable given an accident occurs, as opposed to "active" safety, that is, making the ship less prone to accidents.

\section{Roro ferry losses}

The Herald of Free Enterprise accident in 1987, together with the much more catastrophic Estonia accident that occurred in 1994, have been clearly the events that have critically shaped the development of international regulations for Roro ferry design and operation for year 2000 and beyond. It is fair to say that most of such regulations focus on technological solutions that enhance the survivability of the vessel and the people onboard in case of flooding, rather than prevent the circumstances for the latter to occur. Along with ferry design, they include rules for the evacuation of passengers onboard ferries in case of a serious accident, which are rules that again deal with the mitigation of damage (material and human) once the undesirable event happens.

The new rules for Roro ferry design are more stringent in those European countries that ratified the so-called "Stockholm Agreement", which specifies a flotation capability with 50 $\mathrm{cm}$ of water on the deck. The EU countries that ratified the agreement were Denmark, Finland, Germany, Ireland, Sweden and the UK, and they were joined by Norway. The rest of EU countries (and most notably the Mediterranean countries) fiercely opposed this rule as too drastic. It is clear that the new rules will radically change the composition of the European ferry fleet in the years ahead, because it would be too expensive to retrofit old ferries so that they become compliant. The economic consequences of such a change are unknown, but are speculated to be significant. With many shipping companies heavily in debt and struggling to survive, fleet renewal is not an easy proposition.

Be that as it may, it remains to be seen to what extent these rules, in and of themselves, will actually enhance the safety of Roro ferries. Both the Herald of Free Enterprise and Estonia investigations trace at least part of the reason for these accidents to questionable actions on the part of the master and/or the crew. If these actions had not happened, it is not clear at all that these accidents would have taken place all the same. This sheds some doubt, in my opinion, on the very rationale for the policies that were formulated subsequent to these accidents. 
Fires are also a serious risk factor for Roro ferries and all other passenger ships (particularly cruise ships), given the high number of potential fatalities. All known evidence to date suggests the human element as being responsible for most of such accidents, because of negligence, faulty maintenance, and so on. "Passive", after-the-fact measures, including smoke detectors, fire sensors, sprinklers, fire doors, and fire control procedures should really complement "active" before-the-fact measures that are put in place so that fires are less likely to occur in the first place. Investigation as to which are the best such measures should be undertaken.

\section{Conclusions and recommendations}

I believe that the issues discussed in this paper can support the following general conclusions that are relevant from a maritime safety policy perspective:

1) Maritime safety policy can be characterized by an impressive array of regulations dealing with this subject on many dimensions.

2) If these regulations are responsible for the generally acceptable safety record of maritime transport, they must also be held responsible for the fact that this record needs further improvement.

3) By and large, the sheer number of players developing policy and the sheer number of policy topics have contributed to a "patchwork" picture that may result in over-regulation, overlaps in regulation, inconsistencies in regulation and gaps in regulation.

4) Even though maritime safety policy is claimed to be "proactive", most serious regulatory activities developed recently have been driven by major accidents.

5) Whereas there is very strong evidence that the human element is the main reason for many major accidents, most policies that came in the aftermath of such accidents focus more on technological and design solutions.

6) The bulk of the rules and regulations in this area concerns passive safety and after-thefact vessel survivability, as opposed to preventive rules reducing the likelihood of accidents.

7) Even though the impact on maritime transport of many recent policies is monumental, both benefits and costs of such policies as regards safety remain by and large undocumented.

8) The use of the scientific method in maritime safety is growing, but is still significantly under-developed and so far has had very little impact on policy formulation.

I realize that some or all of these conclusions may be provocative. However, I believe that this is legitimate in order to further stimulate the debate for possible improvements in the maritime safety area.

Specifics aside, to the best of my knowledge, no policy in maritime safety has had a clear target on what explicit improvement in safety it aims to achieve, and this adds to the difficulty of reaching the target. "How safe is safe enough" is the relevant question. If for instance the target was "reduce the frequency of ship collisions by a factor of 10 over the next 5 years", or "reduce the frequency of tanker spills by 5 in 10 years", or whatever other target is set, one would be able to assess the merits (or lack thereof) of the specific measures that were set forth to achieve that target. It would also facilitate very much the comparison among alternative policies for the achievement of this goal.

Central in all this is that nobody knows explicitly society's willingness to pay to achieve safety improvements, and who should be made to pay for these improvements. Questions such as "what price safety", or "who pays for safety" are very commonly asked, but very rarely analyzed in depth. Achieving specific, well-defined safety improvements will certainly come at a price, as there is no "free lunch" in maritime safety. If the policy-maker who will 
ultimately decide on Policy A versus Policy B has little or no idea of either what the benefits or the costs of these policies might be, then his or her choice of policy will be by definition arbitrary and, as such, subject to error and criticism, particularly if something goes wrong afterwards.

It is my opinion that this very serious issue should be the subject of research that would specify how these factors should be used for policy-making purposes. To that end, R\&D projects in the maritime safety area should be launched with the explicit purpose of answering questions that remain unanswered and evaluating policy alternatives in this area. These policy alternatives should be carefully assessed and compared vis-à-vis well defined criteria, so that the policy-maker is aware of the implications of each alternative before making a choice.

Alongside with this, there should be more effort to analyze results of past or ongoing maritime safety R\&D from a policy perspective. For instance, the results of all EU safetyrelated waterborne transport projects could be carefully assessed in terms of possible policy ramifications. This could establish a better link between EU R\&D and EU policy development, and guide the former so as to better assist the latter. It could also move maritime safety policy closer to being proactive than it currently is.

\title{
8. References
}

Barnett, A., 1987. Lightning Strikes Twice. Interfaces 17, pp. 21-26.

Machol, R., A. Barnett, 1988. Thunderstorms and Aviation Safety: A Dialogue. Interfaces 18, pp. 20-27.

Psaraftis, H.N., G. Panagakos, N. Desypris, N. Ventikos, 1998a. An Analysis of Maritime Transportation Risk Factors. ISOPE Conference, Montreal, Canada, May 1998.

Psaraftis, H.N., P. Caridis, N. Desypris, G. Panagakos, N. Ventikos, 1998b. The Human Element as a Factor in Marine Accidents. IMLA -10 Conference, St. Malo, France, October 1998.

\section{Acknowledgments}

Much of the analysis that led to the opinions expressed in this paper was carried out in the context of EU-funded R\&D projects SAFECO, SAFECO II, and CASMET, in which the National Technical University of Athens participated. Of course, I am solely responsible for these opinions. I thank Erik Styhr Petersen of Lyngsoe Marine for suggesting ways to improve a previous version of this paper.

\section{ANNEX A}

\section{DAMA - Casualty cause codes (source: Det Norske Veritas)}

\author{
Code Description \\ A Circumstances not related to the ship \\ A01 Very heavy weather, natural disaster etc. \\ A02 Current, wind etc. led to strong drift or other maneuver difficulties. \\ A03 Collided with floating objects, could not be discovered/avoided in time. \\ A04 Fault with navigation systems: lights, external electronic systems etc. \\ A05 Fault with charts or publications. \\ A06 Technical fault with other ship (also includes towboats and the like). \\ A07 Operational fault with other ship (wrong maneuver/poor seamanship etc.).
}


Technical fault with load/unload/bunker construction/quay/sluice, outside the ship. Wrong handling of load/unload/bunker construction/quay/sluice, outside the ship. Blowout or other extern conditions in connection with oil drilling.

A11 Other conditions outside the ship.

B Construction of the ship and location of equipment on board

B01 The ship's structural strength not sufficient.

B02 The structural strength weakened by later welding jobs, corrosion etc.

B03 Stability failure caused by the construction of the ship.

B04 The ship had too poor maneuver qualities.

B05 The arrangement of the engine room/location of equipment with danger of leakage/setting on fire.

B06 Unfortunate arrangement or location of load- or storage room.

B07 Unfortunate location/arrangement of other rooms on board (not bridge).

B08 Difficult access for cleaning, maintenance and inspection.

B09 Other conditions concerning the construction and maintenance of the ship.

C Technical conditions concerning equipment on board

C01 Technical fault with navigation equipment.

C02 Technical fault with steering systems.

C03 Technical fault with propulsion systems.

C04 Technical fault with auxiliary engine.

C05 Technical fault with anchorage equipment/deck machinery (not load/unload equipment).

C06 Technical fault with control/remote control/automatic controls/warning equipment.

C07 Technical fault with loading or unloading device.

C08 Technical fault with preparedness/safeguarding/inert gas/halogen equipment.

C09 Technical fault with equipment.

C10 Other technical conditions concerning equipment on board.

D Conditions concerning use and design of equipment

D01 Unfortunate design of the bridge, lacking or wrong location of equipment.

D02 Illogical/wrong design of controls, steering systems etc.

D03 The equipment was not placed where it was natural to use it.

D04 Illogical/inappropriate/poor/worn out equipment. More easily accessible.

D05 Other conditions concerning use/design of equipment. Man/engine problems.

E Cargo, safeguarding and treatment of cargo and bunkers

E01 Self-ignition in cargo/bunker, also by «sloshing» in tanks.

E02 Lacked inert gas installation or other safeguarding against explosion/fire.

E03 Stability not according to regulations (wrong placing of cargo/lacking ballast etc.).

E04 The cargo was not sufficiently safeguarded against shifting.

E05 Leakage of liquid cargo in casks, containers, tanks, etc.

E06 Breaks in loading or bunker pipes.

E07 Other conditions concerning cargo and safeguarding cargo and bunkers.

F Communication, organization, procedures and routines

F01 Routines for average control were lacking/were not sufficient.

F02 Existing routines for average control were not properly known/drilled.

F03 Routines for safety control lacked/were not sufficient.

F04 Existing routines for safety control known, but not followed.

F05 Did not follow the safety regulations for welding.

F06 Welding led to accident even though the safety regulations were followed.

F07 Not taken measures concerning testing of rescue instruments etc.

F08 Did not use protective equipment. 
F09 The general level of organization/routines/qualifications poor.

F10 Failure of routines for inspection and maintenance on board.

F11 Stability not known, approved stability calculations were not available.

F12 Unfortunate management, personal antagonisms or suchlike.

F13 Too small crew, generally or for the task e.g. helmsman/look-out.

F14 Command or distribution of responsibility was or was perceived as unclear.

F15 Not established safety routines in connection with navigation/maneuvering (bridge watch).

F16 Safety routines in connection with navigation/maneuvering known, but not followed.

F17 Charts/other documents for the voyage were not amended.

F18 Failure of procedure/co-operation between vessel/towboat, organization from the shore or suchlike.

F19 Other conditions concerning routines, procedures, communication or organization.

G Individual on board, situation judgment, reactions

G01 Insufficient formal competence for the task (courses, exams etc.).

G02 Insufficient real competence (practice from occupation, waters, with equipment or suchlike).

G03 Task not well planned (cargo, night voyage, maneuvering, anchoring etc.).

G04 Available means of warning not sufficiently used.

G05 Alternative navigation systems not used misjudged lanterns etc.

G06 Available navigation aids not used (Norwegian Pilot etc.).

G07 Not adequate observation of own position/not plotted on charts.

G08 Misjudgment of other vessel's movement or intention.

G09 Misjudgment of own vessel's movements (current, wind etc.).

G10 Tried to go through with the operation even though the conditions were not favorable.

G11 Did not keep to the starboard in the waters.

G12 Kept up a faster than safe pace.

G13 Special conditions (illness, little sleep, a lot of work etc.).

G14 Fell asleep on watch.

G15 Alcohol or other intoxicant.

G16 Other conditions concerning individuals. 